\title{
The effect of polymorphic inversions on body size in two natural populations of Drosophila buzzatii from Argentina
}

\author{
JUAN J. FANARA, ESTEBAN HASSON and CONSTANTINA RODRÍGUEZ \\ GIBE, Departmento de Ciencias Biológicas. Facultad de Ciencias Exactas y Naturales, Universidad de Buenos \\ Aires, Ciudad Universitaria Pab. II. (1428) Buenos Aires, Argentina
}

\begin{abstract}
Fanara, J. J., Hasson, E. and Rodriguez, C. 1997. The effect of polymorphic inversions on body size in two natural populations of Drosophila buzzatii from Argentina. - Hereditas 126: 233-237. Lund, Sweden. ISSN 0018-0661. Received January 8, 1997. Accepted May 22, 1997

Previous works in a colonized and an original population of Drosophila buzzatii have shown a consistent relationship between the inversion polymorphism and thorax length, a measure of body size. However, the populations studied in those reports share a close genealogical relationship as suggested by several lines of evidence. In the present paper, we revisit this issue by analysing the correlation between second chromosome arrangements and thorax length in two Argentinian natural populations (Termas de Rio Hondo and Arroyo Escobar) from different biogeographic areas with different host plants. Our findings are: (1) inversion frequencies were significantly different between populations; (2) the mean thorax length of flies collected in both populations was not significantly different; and (3) we obtain confirming evidence that flies carrying 2 st, the ancestral gene order, have on average a smaller body size than those carrying the derived arrangements $\left(2 \mathrm{j}\right.$ and $\left.2 \mathrm{jz}^{3}\right)$. These results suggest that the biometrical effect of inversions on body size previously described are due to genetic differences between arrangements and not to the close historical relationship between the populations studied in previous reports.
\end{abstract}

Juan J. Fanara, GIBE, Departamento de Ciencias Biológicas, Facultad de Ciencias Exactas y Naturales, Universidad de Buenos Aires, Ciudad Universitaria Pab. II. (1428) Buenos Aires, Argentina. E-mail: fanara@biolo.bg.fcen.uba.ar

Body size is an easily observable trait that is related with fitness. In recent years, several studies have shown in Drosophila that body size is positively correlated with adult fitness components in nature, as mating success (PARTRIDGE et al. 1987; SANTOS et al. 1988, 1992; NORRY et al. 1995b), longevity (SANTOS et al. 1992; Hasson et al. 1993), and fecundity (PARTRIDGE 1988; SANTOS et al. 1992). In addition, body size has also been shown to be correlated with dispersal potential (Roff 1977).

However, it might be argued that these observations can be the result of just phenotypic selection, since body size is a trait strongly influenced by environmental variation, or due to correlated selection acting on related traits. For instance, NORRY et al. (1995b) reported, in the cactophilic Drosophila buzza$t i i$, that another size-related trait, face width, can account for the pattern of differential male mating success observed for body size in the Argentinian population of Arroyo Escobar.

In $D$. buzzatii a consistent relationship between body size and inversion polymorphism has also been shown in two natural populations, one from the recently colonized Mediterranean area: Carboneras, Spain (Ruiz et al. 1991) and the other from Argentina, Arroyo Escobar (HASson et al. 1992; NORRY et al. 1995a). These results suggest that the patterns of directional selection favouring larger flies described for mating success (SANTOS et al. 1988) and longevity (SANTOS et al. 1992; HASSON et al. 1993) can have genetic significance and that the inversion polymorphism may be, at least in part, the genetic basis of the selective mechanism.

However, it might be important to point out that the origins of both populations are recent. FONTDEVILA (1989) argued that the Spanish population might be no older than two hundred years, and the Argentinian one might be no older than one hundred (FAnARA et al. 1996). Moreover, FontDEvila (1989) suggested, based on the sharing of rare electrophoretic alleles and chromosomal arrangements, that individuals from a population similar to Arroyo Escobar would have been the original founders of Old World populations. Therefore, the correlation between body size and inversion polymorphism observed in both populations may be the result of this close historical relationship.

In the present paper, we investigate the effects of the inversion polymorphism on body size in $D$. buzzatii wild flies collected in two geographically distant populations in Argentina, one from the putative center of origin, the Western Chaco Phytogeographic Province (according to CABRERA 1976), at Termas de Río Hondo and the other, Arroyo Escobar, located in the margins of the present distribution in the Pampa Phytogeographic Province. 


\section{MATERIALS AND METHODS}

In Arroyo Escobar, D. buzzatii breeds and feeds on the rotting cladodes of Opuntia vulgaris (HAssON et al. 1991, 1992), and in Termas de Río Hondo the main resources are the cladodes of $O$. quimilo and $O$. ficus-indica., although other cactus species are present (HASSON et al. 1995; FANARA et al. 1996). We used net sweeping over fermented banana baits in Arroyo Escobar. In Termas de Río Hondo, rotting cladodes of $O$. quimilo and $O$. ficus-indica were employed as natural traps, and attracted flies were collected by aspiration (FANARA et al. 1996).

Adult flies were separated by sex immediately upon arrival to the laboratory. Each male was crossed individually with two virgin females homozygous for arrangements $j$ in the second and $s$ in the fourth chromosome, and offspring were reared in a modified formula of DAvID's (1962) killed yeast culture medium. The trios were transferred to new vials with fresh food after $48 \mathrm{~h}$ to avoid larval crowding. Males were aspirated off the vials, anesthetized and scored for thorax length, the distance from the anterior margin to the posterior tip of the scutellum in lateral view. The trait was measured with a binocular microscope fitted with an ocular micrometer. From each vial showing offspring, one larva was processed for cytological analysis according to the technique described in FonTDEVILA et al. (1981).

\section{Statistical analysis}

Since, in Termas de Río Hondo, the flies were collected using the rotting cladodes of $O$. quimilo and $O$. ficus-indica as attractants, we examined whether the mean thorax length of flies attracted to the two cactus species are different. A two-factor ANOVA with cactus species (fixed) and inversion (fixed) was used to test this effect.

To compare the biometrical effects of inversions on thorax length an ANOVA with population and inversion as fixed factors was performed.

Prior to the ANOVAs all measurements of thorax length were log-transformed.

\section{RESULTS}

Second chromosome inversion frequencies in the samples of adult males collected in Termas de Río Hondo on $O$. ficus-indica and $O$. quimilo rotting cladodes were not significantly different (FANARA et al. 1996). Arrangement frequencies estimated after pooling across Opuntia hosts (447 individuals analysed) were: $\mathrm{st}=0.60, \mathrm{j}=0.38$, and $\mathrm{jz}^{3}=0.02$ (Fig. 1)

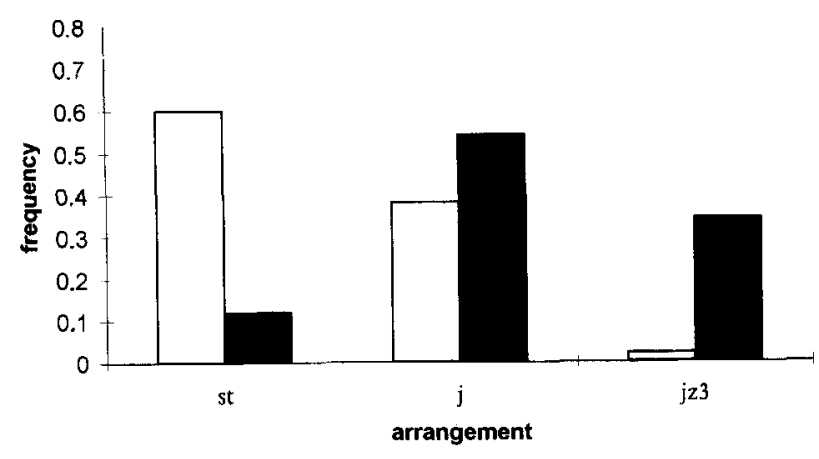

Fig. 1. Frequencies of second chromosome arrangements in the $D$. buzzatii natural populations of Termas de Rio Hondo (open bars) and Arroyo Escobar (solid bars)

Due to the low number of individuals bearing arrangement $\mathrm{jz}^{3}$ they were pooled with those carrying arrangement $j$ ( $2 j$ phylad hereafter) to investigate the biometrical effect of inversions on thorax length. The validity of this procedure is well supported, since these two arrangements are cytologically derived compared with 2st, which is the species' ancestral gene order (Ruiz et al. 1982).

The thorax lengths were not significantly different $\left(F_{1.346}=0.23, p=0.63\right)$ between wild males collected on O. ficus-indica and O. quimilo (Table 1). However, mean thorax length differences between flies carrying different second chromosome arrangements were highly significant $\left(F_{1,346}=9.91, p=0.002\right)$, suggesting that, at Termas de Río Hondo, flies carrying inversions of the $2 \mathrm{j}$ phylad are significantly larger than those bearing 2st (Table 1, Fig. 2) (we will return to this issue below). The inversion by cactus interaction was non significant, i.e., the effects of inversions on thorax length were identical between cactus hosts. Therefore, these samples were pooled to compare between populations.

Table 1. Mean thorax length (in $m m \pm$ standard error) for the samples of $D$. buzzatii adult fies collected on the rotting cladodes of $O$. ficus-indica and $O$. quimilo in the population of Termas de Río Hondo. The corresponding mean values for fies carrying each second chromosome arrangement (see text explanation) in each sample are also shown. N: number of individuals analysed

\begin{tabular}{|c|c|c|c|c|}
\hline & \multicolumn{2}{|c|}{ o. ficus-indica } & \multicolumn{2}{|c|}{ o. quimilo } \\
\hline & st & $\mathrm{j}$ & st & $j$ \\
\hline $\bar{x}$ & $\begin{array}{r}0.968 \\
\pm 0.006\end{array}$ & $\begin{array}{r}0.983 \\
\pm 0.008\end{array}$ & $\begin{array}{r}0.960 \\
\pm 0.006\end{array}$ & $\begin{array}{r}0.987 \\
\pm 0.007\end{array}$ \\
\hline $\mathrm{N}$ & 111 & 60 & 102 & 77 \\
\hline Mean & & & & \\
\hline
\end{tabular}




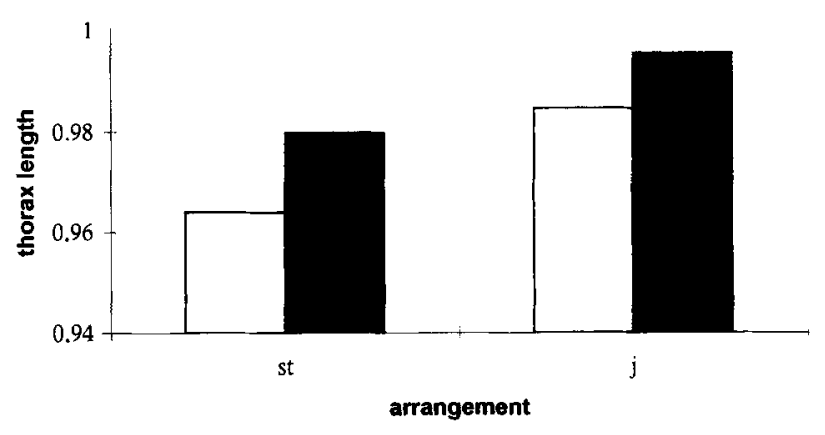

Fig. 2. Mean thorax length in $\mathrm{mm}$ of flies carrying arrangement st and of the $j$ phylad (see text for explanation) in the natural populations of Termas de Río Hondo (open bars) and Arroyo Escobar (solid bars)

Inversion frequencies in the population of Arroyo Escobar estimated from a sample of 612 adult males were: $s t=0.12, j=0.54$, and $\mathrm{jz}^{3}=0.34$ (Fig. 1). The between-population comparison of inversion frequencies by means of a contingency test showed highly significant differences $\left(\chi^{2}=324.7, \quad \mathrm{df}=2, \quad P<\right.$ 0.0001 ).

The same pooling procedure employed in Termas de Río Hondo (2st vs $2 \mathrm{j}$ phylad) was also used in Arroyo Escobar.

Mean thorax length of flies collected in both populations (Table 2) did not differ $\left(F_{1,682}=2.54, p=\right.$ 0.11 ). However, the ANOVA confirm that thorax length differences between arrangements $2 \mathrm{st}$ and $2 \mathrm{j}$ were highly significant $\left(\mathrm{F}_{1,682}=8.64, p=0.003\right)$, particularly in Termas de Río Hondo $(t=2.69, p=$ 0.008 ), while in Arroyo Escobar this effect was non-significant $(t=1.55, p=0.12)$.

Table 2. Mean thorax length (in $\mathrm{mm} \pm$ standard error) for the samples of D. buzzatii adult flies collected in the natural populations of Termas de Rio Hondo and Arroyo Escobar (Argentina), along with the corresponding mean values for flies carrying arrangements $2 s t$ and those of the $2 j$ phylad. $N$ : number of individuals analysed

\begin{tabular}{|c|c|c|c|c|}
\hline & \multicolumn{2}{|c|}{ Termas de Rio Hondo } & \multicolumn{2}{|c|}{ Arroyo Escobar } \\
\hline & st & $\mathrm{j}$ & st & $\mathbf{j}$ \\
\hline$\overline{\mathrm{X}}$ & $\begin{array}{r}0.964 \\
\pm 0.005\end{array}$ & $\begin{array}{r}0.985 \\
\pm 0.006\end{array}$ & $\begin{array}{r}0.980 \\
\pm 0.009\end{array}$ & $\begin{array}{r}0.996 \\
\pm 0.005\end{array}$ \\
\hline $\mathrm{N}$ & 213 & 137 & 65 & 278 \\
\hline Mean & \multicolumn{2}{|c|}{$\begin{array}{r}0.973 \\
\pm 0.003\end{array}$} & \multicolumn{2}{|c|}{$\begin{array}{r}0.993 \\
\pm 0.005\end{array}$} \\
\hline
\end{tabular}

\section{DISCUSSION}

Two main conclusions can be drawn from the present study, first, the absence of significant thorax length differences between flies collected in two geographically distant populations and, second, the corroboration of the existence of a correlation between second chromosome inversion arrangements and thorax length in D. buzzatii.

The first observation is relatively unexpected since body size is a trait that is strongly influenced by environmental variables (GRIMALDI and JAENIKE 1984; ETGES and HeED 1987; ROBERTSON 1987; THOMAS 1993) such as temperature, which has been suggested as the main determinant of the latitudinal clines observed for body size in several species (e.g., Prevosti 1955; MisRa and Reeve 1964).

Particularly, in $D$. buzzatii laboratory analysis clearly shows that adult body size is negatively correlated with temperature during larval development (ROBERTSON 1987). However, flies in Arroyo Escobar were not larger than in Termas de Río Hondo, despite mean annual $\left(20^{\circ} \mathrm{C}\right)$ as well as the temperature during the collecting period in the former were lower than in the latter $\left(25^{\circ} \mathrm{C}\right)$.

Previous work in $D$. buzzatii revealed that arrangement 2 st has a decreasing effect on thorax length, while flies carrying arrangements of the $2 \mathrm{j}$ phylad $(\mathrm{j}$, $\mathrm{jz}^{3}$ and $\mathrm{jq}^{7}$ ) are on average larger (RuIz et al. 1991; HASSON et al. 1992; NoRRY et al. 1995a).

In this report, the effect of second chromosome arrangements on thorax length in Termas de Río Hondo and Arroyo Escobar were similar to those reported for wild and laboratory flies from Carboneras (RUIZ et al. 1991) and laboratory flies from Arroyo Escobar (HAsson et al. 1992). However, the effect of inversions on thorax length was only significant in Termas de Río Hondo and not in Arroyo Escobar. There are two possible explanations for this difference. On one hand, it can be argued that this could be a statistical problem due to the low number of 2 st individuals sampled in Arroyo Escobar. On the other hand, the absence of significant effects would be related to our previous observation of longevity selection favouring larger flies in Arroyo Escobar (HASSON et al. 1993). Thorax length differences between flies carrying different arrangements would be obscured if selection favoured larger $2 \mathrm{st}$ and $2 \mathrm{j}$ bearing individuals. In effect, a sample of flies newly emerged from the rotting cladodes of $O$. vulgaris showed a significant karyotypic component of variation for thorax length, while a simultaneous sample of bait collected flies, after longevity selection, did not (Rodríguez, HASSON and FANARA, unpublished results), giving support to the second alterna- 
tive. Likewise, the inversion by population interaction was not significant, suggesting that the effect is homogeneous across populations, despite the fact that $D$. buzzatii encounters varying environments, including Opuntia hosts and climate.

FANARA et al. (1996) argued that Arroyo Escobar and the Spanish population of Carboneras have a recent origin. The former is located in the Southern edge of the D. buzzatii present distribution (HASSON et al. 1995), and FonTDEVILA (1989) claimed that the founders of Spanish populations, such as Carboneras, might have originated in a population similar to Arroyo Escobar. Thus, the significant effect of second chromosome inversions on thorax length observed in Termas de Río Hondo suggests that previous observations in Arroyo Escobar (HASSON et al. 1992) and Carboneras (Ruiz et al. 1991) are not due to their recent common history, but to genetic differences that seem very ancient.

In previous papers we advanced the hypothesis that fitness differences among inversions revealed by means of selection component analysis in $D$. buzzatii can be mediated by their effects on body size (HASSON et al. 1992; NORRY et al. 1995a). Moreover, based on the positive correlation between body size and adult fitness components (SANTOS et al. 1988; HASSON et al. 1993) it was proposed that arrangement 2 st may reduce fitness during the adult stage. In Arroyo Escobar, we observed that carriers of this arrangement have a decreased longevity, which is counteracted by its positive effect during the pupal stage (HASSON et al. 1991). However, a similar study in Termas de Río Hondo (FANARA et al. 1996) contrasted sharply with our survey in Arroyo Escobar, despite that the effect of inversions on body size is similar in both populations.

Therefore, it can be concluded that the relationship between body size, karyotype, and fitness components is complex.

\section{ACKNOWLEDGMENTS}

The authors wish to thank M. Santos for help in field and lab work, and an anonymous reviewer for suggestions to improve earlier versions of the manuscript. We wish to express our gratitude to Prof. Antonio Fontdevila for permanent encouragement. EH is member of Carrera del Investigador Científico of CONICET (Argentina). This work was supported by Universidad de Buenos Aires grant EX 099/94 awarded to EH.

\section{REFERENCES}

Cabrera A, (1976). Regiones fitogeográficas de la Argentina. Enciclopedia de la Argentina de agricultura y ganadería. ACME SACI. Buenos Aires.
David J, (1962). A new medium for rearing Drosophila in axenic conditions. Drosophila Inf. Serv. 36: 128.

Etges WJ and Heed WB, (1987). Sensitivity to larval density in populations of Drosophila mojavensis: influences of host plant variation on components of fitness. Oecologia 71 : $375-381$.

Fanara JJ, Hasson E, Rodríguez $C$, Santos $M$ and Fontdevila A, (1996). Are Opuntia hosts a selective factor for the inversion polymorphism of Drosophila buzzatii? Heredity 77: $500-506$.

Fontdevila A, (1989). Founder effects in colonizing populations. The case of Drosophila buzzatii. In: Evolutionary Biology of Transient Unstable Populations (ed. A. Fontdevila) Springer-Verlag. Berlin, p. 74-95.

Fontdevila A, Ruiz A, Alonso G and Ocana J, (1981). Evolutionary history of Drosophila buzzatii. I. Natural chromosomal polymorphism in colonized populations of the Old World. Evolution 35: 148-157.

Grimaldi DA and Jaenike $\mathbf{J}$, (1984). Competition in natural populations of mycophagous Drosophila. Ecology 65: $1113-1120$.

Hasson E, Vilardi JC, Naveira H, Fanara JJ, Rodríguez C, Reig OA and Fontdevila A, (1991). The evolutionary history of Drosophila buzzatii. XVI. Fitness components analysis in a natural original population from Argentina. J. Evol. Biol. 4: 209-225.

Hasson E, Fanara JJ, Rodriguez C, Vilardi JC, Reig OA. and Fontdevila A, (1992). The evolutionary history of Drosophila buzzatii. XXIV. Second chromosome inversions have different average effect on thorax length. Heredity 68: $557-563$.

Hasson E, Fanara JJ, Rodríguez C, Vilardi JC, Reig OA. and Fontdevila A, (1993). The evolutionary history of Drosophila buzzatii XXVII. Thorax length is positively correlated with longevity in a natural population from Argentina. Genetica 92: 61-65.

Hasson E, Rodríguez C, Fanara JJ, Naveira H, Reig OA and Fontdevila A, (1995). The evolutionary history of Drosophila buzzatii. XXXI. Macrogeographic patterns of inversion polymorphisms in New World populations. J. Evol. Biol. 8: 369-384.

Misra RK and Reeve ECR, (1964). Clines in body size dimension in populations of Drosophila subobscura. Genet. Res. 5: 240-256.

Norry FM, Vilardi JC, Fanara JJ, Rodriguez C and Hasson $E$, (1995a). An adaptive chromosomal polymorphism affecting size-related traits and longevity selection in a natural population of Drosophila buzzatii. Genetica 96 : 285-291.

Norry FM, Vilardi JC, Fanara JJ and Hasson E, (1995b). Sexual selection on morphometric traits in Drosophila buzzatii. J. Insect Behav. 8: 219-229.

Partridge L, (1988). Lifetime reproductive success in Drosophila. In: Reproductive Success (ed. T.H. CluttonBrock) University of Chicago Press. Chicago, p. 11-23.

Partridge L, Hoffman A and Jones JS, (1987). Male size and mating success in Drosophila melanogaster and D. pseudoobscura under field conditions. Anim. Behav. 35: $468-476$

Prevosti A, (1955). Geographic variability in quantitative traits in populations of Drosophila subobscura. Cold Spring Harbor Symp. Quant. Biol 20: 294-299.

Robertson FW, (1987). Variation of body size within and between wild populatons of Drosophila buzzatii. Genetica $72: 111-125$ 
Roff DA, (1977). Dispersal in dipterans: its costs and consequences. J. Anim. Ecol. 46: 443-456.

Ruiz A, Fontdevila A and Wasserman M, (1982). The evolutionary history of Drosophila buzzatii. III. Cytogenetic relationships between two sibling species of the buzzatii cluster. Genetics 101: 503-518.

Ruiz A, Santos M, Barbadilla A, Quesada-Diaz J, Hasson E and Fontdevila A, (1991). The evolutionary history of Drosophila buzzatii. XVIII. Genetic variance for body size in a natural population. Genetics 128: 739-750.

Santos M, Ruiz A, Barbadilla A, Quezada-Dia J, Hasson E and Fontdevila A, (1988). The evolutionary history of Drosophila buzzatii. XIV. Larger flies mate more often in nature. Heredity 61: 255-262.

Santos M, Ruiz A, Quezada-Diaz J, Barbadilla A and Fontdevila A, (1992). The evolutionary history of Drosophila buzzatii. XX. Positive phenotypic covariance between field adult fitness components and body size. J. Evol. Biol. 5: 403-422.

Thomas RH, (1993). Ecology of body size in Drosophila buzzatii: untangling the effects of temperature and nutrition. Ecol. Entomol. 18: 84-90. 